Education \& Training | Eleanor Hawe \& Helen Dixon

\section{How to use exemplars and rubrics to improve student outcomes}

\begin{tabular}{|c|c|}
\hline $\begin{array}{l}\text { Associate Professors in the } \\
\text { Faculty of Education and } \\
\text { Social Work at the University } \\
\text { of Auckland, Eleanor Hawe } \\
\text { and Helen Dixon, specialise } \\
\text { in evaluating and improving } \\
\text { learning assessments. Eleanor } \\
\text { is isterested in goal setting, } \\
\text { feedback, and peer review. } \\
\text { Helen focuses on teachers' } \\
\text { beliefs and their effect on } \\
\text { learning. In their study, 'Using } \\
\text { rubrics and exemplars to } \\
\text { develop students' evaluative } \\
\text { and productive knowledge } \\
\text { and skill', they spent time } \\
\text { observing and interviewing } \\
\text { students to see how they } \\
\text { used exemplars and rubrics to } \\
\text { improve their work. }\end{array}$ & $\begin{array}{l}\text { any students, at all levels } \\
\text { of education, know the } \\
\text { assessment outcome they wan } \\
\text { to attain but feel lost and confused } \\
\text { about how to go about assessment } \\
\text { tasks so they can successfully achieve } \\
\text { the desired outcome. To address this, } \\
\text { educators (lecturers, teachers) are } \\
\text { making increasing use of exemplars } \\
\text { and rubrics. These tools give students } \\
\text { an idea of what constitutes quality } \\
\text { in the task at hand. Hawe and Dixon } \\
\text { are interested in analysing the value } \\
\text { of exemplars and rubrics and, in } \\
\text { particular, how they help students to } \\
\text { make evaluative judgements, as well } \\
\text { as how they can be used to encourage } \\
\text { student self-monitoring, and how they } \\
\text { can increase students' productive } \\
\text { knowledse and skills. }\end{array}$ \\
\hline
\end{tabular}

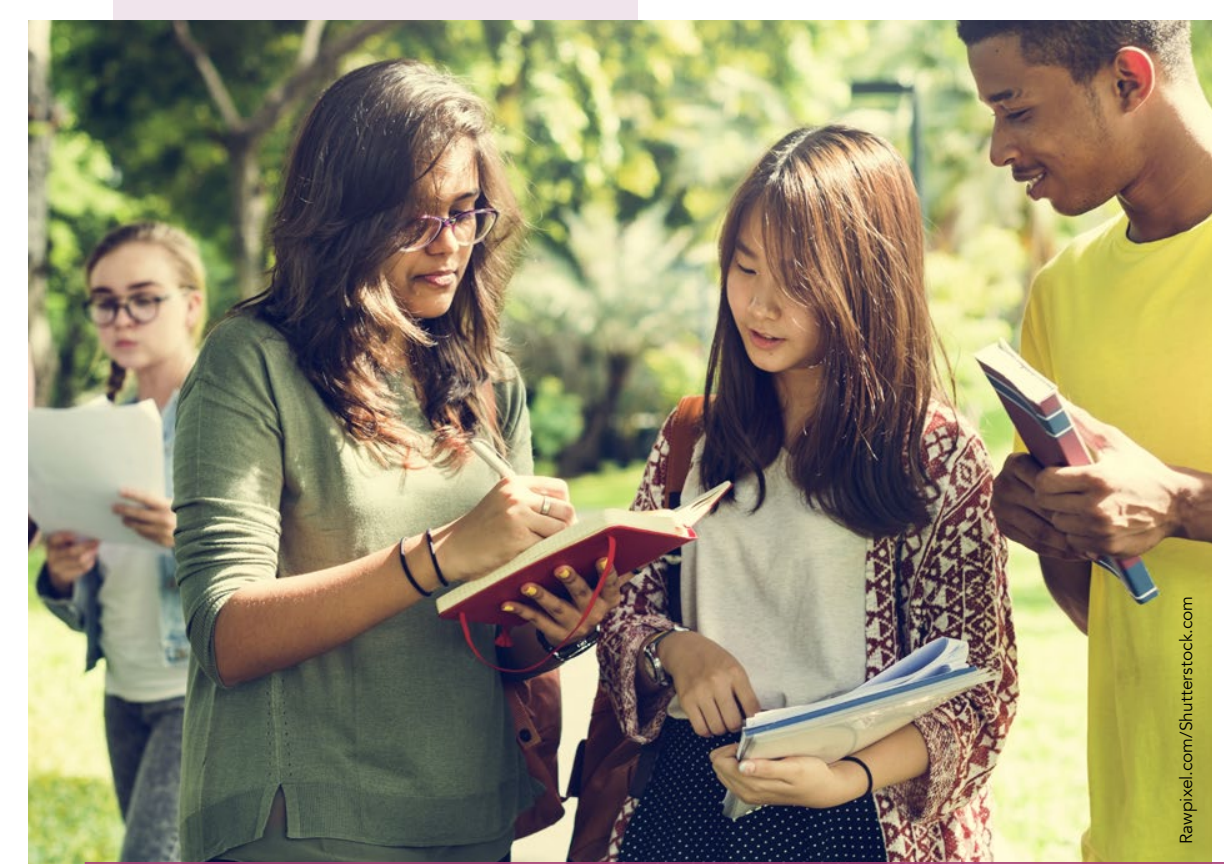

THE VALUE OF RUBRICS

AND EXEMPLARS

The argument underlying the use of

are used purposefully, they can help

students understand the standard of

work expected and as a result, students

can work towards achieving the desired

level of attainment. The use of these tools

is becoming an increasingly common

feature of teaching practice in universities.

Associate Professors in the Faculty

of Education and Social Work at the

University of Auckland, Eleanor Hawe and

Helen Dixon, have explored, in a number

of studies, why and how educators

integrate rubrics and exemplars into their

teaching practice and how students use

task achievement.

Previous research has suggested that rubrics are generally useful for students but they need to be used in context. Their most powerful impact on learning and achievement comes when they are used in association with exemplars. Fundamentally, students need to acquire the same complex knowledge that or assessors of their work. This can be achieved through the productive and dialogic use of rubrics and exemplars. The latter are carefully selected samples of authentic student work from previo cohorts, chosen because they typty students use rubrics to any. When of quality work from previous cohorts,

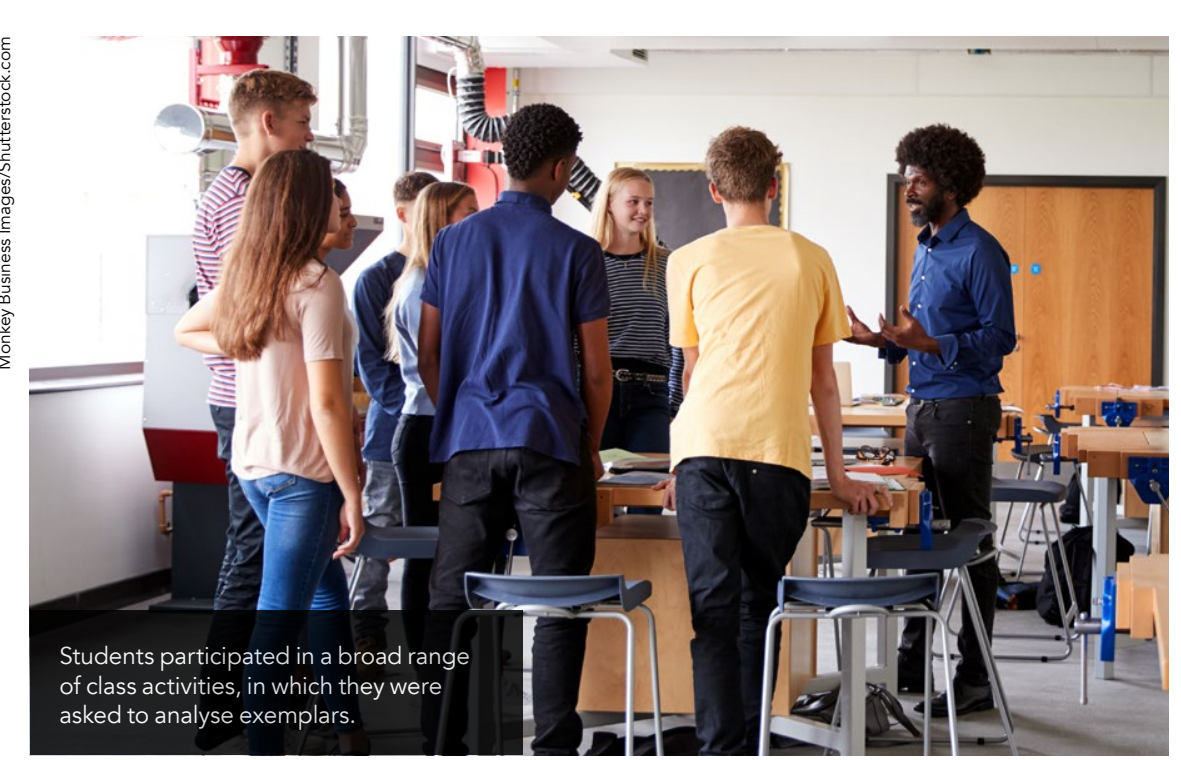

they become better at making wise and sound judgements about the quality of sound york ments about he qualy of

whe

With these ends in mind, students should be given the chance to use rubrics as the decisions about their relative quality. This may involve assigning marks qualty. This

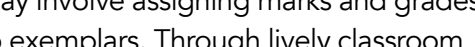
discussions,

dialogue with peers and teachers, and

through group presentations,

students gradually

become better at

recognising the

elements of quality work. In exploring wow ane som, Hawe of sudies, to answer two questions. First, why and how do educators use rubrics and exemplars? And second how do student teachers use rubrics and exemplars when working on their own tasks?

\title{
HOW THE RESEARCH
}

WAS CONDUCTED

their most recent project, Hawe and Dixon used an interpretive and qualitative research approach to address the ways in which teachers and students used these tools. The participants in this study were two teacher educators who greed to take part and exemplas in the class of

involved students in three classes, in two different courses. The first was a second 57 students, tauht by woth a class of This class took place twice a week for ten weeks. The second was a third year professional education course, with two classes of 39 and 35 students, each class taught by one of the teacher educators This course also took place twice a week for ten weeks. Secondly, the open codes were grouped reflected relationships between codes codes, and were used to determine key themes. Analysis of the data reveled two important themes: teachers used a deliberate and scaffolded approach when using rubrics and exemplars; and student used these tools as points of reference when working on their assessment tasks.

\section{KEY FINDINGS}

In terms of the deliberate scaffolded use of rubrics and exemplars, the two educators implemented a range of structured whole class and small group activities with the purpose of fanillarising students with task expectations and what counted as quality work. These activites included lecturer explanations of and student discussions tandards, modelling of hro criteria the latter to student work (exemplars). questioning of students and summing up

of group and class ideas. When working in small groups, students were able to discuss what they thought key words and phrases in the rubrics meant. For instance one of the lecturers asked the class to talk (rubrics, exemplars and students" and critically, another thought it meant ssignment work-in-progress) and semi- referencing theorists, tructured interviews with students. $\begin{gathered}\text { while a third student } \\ \text { suggested it meant }\end{gathered}$

To collect data, the researchers used in-class observations, the collection of assictics, exemplars, and studen ts structured inteniews with students. The researchers began by simply observing to see how classes were structured. They then focused on observing sessions where rubrics and exemplars were utilised by the two course educators.

Interviews were then transcribed and analysed, along with the observation (field) notes, artefacts used during teaching (rubrics, exemplars) and artefacts gather from the students (works-in-progress, completed assignments). The researchers used the constant comparative method to analyse these data. In the first ins con

discussion, the three students in this group built a shared and solid understanding of what the term meant and how it could be applied to their work. Students also participated in a range of in-class activities where they analysed exemplars, and discussed and made judgements about their strengths and weaknesses with contained in the rubrics.

Regarding students' use of rubrics and exemplars, Hawe and Dixon found these when students were planning how to address the task and statting work on their points of compand, hey were used as working on their task and making revisions 


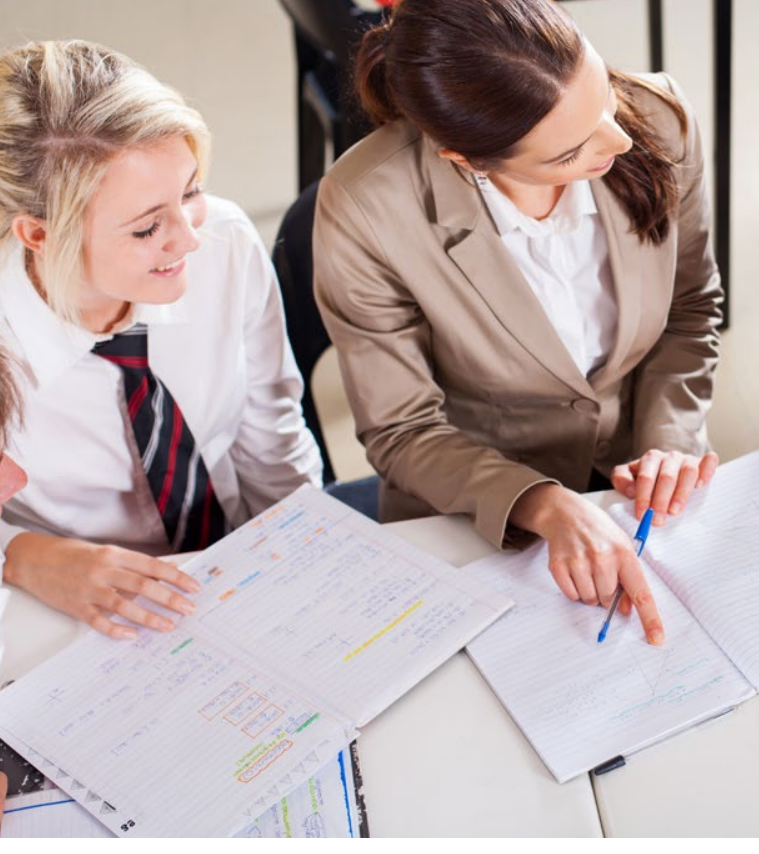

PLANNING AND REVIEWING WORK When planning and constructing their work, students turned to rubrics and exemplars for guidance. They used these
tools to give them ideas about how to tools to give them ideas about how to start their piece of work, how to structure it
and which literature was particularly useful. In addition, they referred to exemplars to help solve specifici issues that arose they were writing, for example, how to they wrercate for example, how to principle, how to make links between theory and practice and the amount of detail to include in a discussion.

When students had a reasonably complete piece of work, or a first dratt, they then compared this work-in-progress to rubrics and exemplars, flicking back and forth between the two so they could check whether they had met requirements and how well the work measured up to specific levels of achievement on the rubric. Some student
used separate browser tabs on their computers to support this process while others preferred to work with paper copies. This gave them the chance to critique and regulate their performance, allowing them to make the changes needed to improve their work. Students would often highlight sentences that didn't match the rubrics or the exemplar. For example, when this process of comparison indicated that an idea was too vague or not clearly explained, it was rewritten to bring it closer to what was expected.

\section{LESSONS LEARNT}

Hawe and Dixon's research has helped to fill a gap in our understanding about how educators can effectively use rubrics and exemplars in their teaching to stimulate
student self-monitoring and self-regulation. and working with rubrics and exemplars, in whole class and small group situations their own work and mane inp crique before submitting their final version.

Hefor submiting teir fin

Hawe and Dixon note in their discussion that teachers are often reluctant to use exemplars because they may stifle taking their own approach to a piece of work. However, they found that the educators counter this by using multiple exemplars, so students can see that there are many different ways to approach the same topic. Exemplars thus act as a form of inspiration, helping students to get started and to structure their work. It does not affect their ability to produce original creative, and high-quality work - in fact exemplars can increase student selfto do better.

xemplars and rubrics should be an rubrics and exemplars by teachers helps
students to build up a clear understanding
study by Hawe and Dixon has helped to Exemplars and rubrics should these tools can be. In particular, be an integral part of the they foster students' ability to teaching process.

of what constitutes quality work, allowing what constudent's understanding of them to gather the knowledge and utilise what constitutes quality work evolves over the strategies needed to complete a their teacher and peroge with both task to a high standard. Students, armed work with rubrics and exemplars. Not with evaluative knowledge similar to only do exemplars and rubrics improve that of their teachers, are better able to productive knowledge, they also help an academic task. As a ressult of analysing regulating learners.

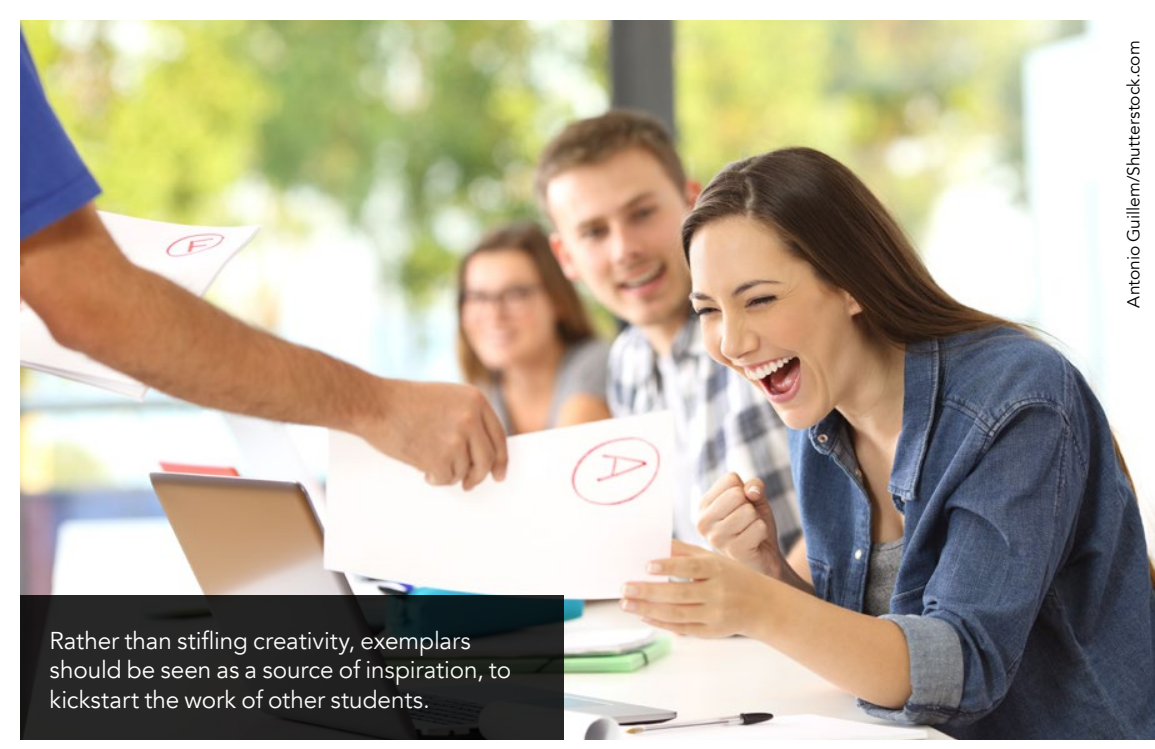

\section{Behind the Research}

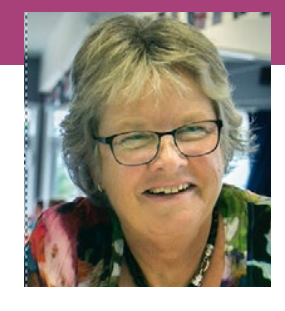

\section{Eleanor \\ Hawe}

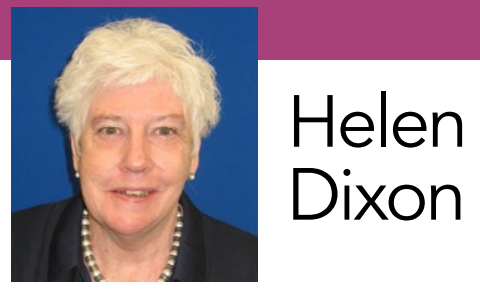

E: e.hawe@auckland.ac.nz E: h.dixon@auckland.ac.nz T: 6496238899

Research Objectives

Eleanor Hawe and Helen Dixon examine how exemplars and rubrics are used by educators and students and explore their impact on student thinking and behaviour.

\section{Detail}

\section{Address}

Faculty of Education, The University of Auckland New Zealand.

Bio

Eleanor Hawe and Helen Dixon are Associate Professors in the Faculty of Education and Social Work at the University of Auckland. Eleano's's research focuses on assessment for learning (including goal setting, feedback, peer review) with attention paid to the use of exemplars to develop student evaluative and productive expertise across a range of educational contexts and teaching subjects. Helen's teaching and research are also focused on assessment for learning within the schooling sector and higher education. In addition beliefs, and how these influence assessment pracice.

\section{Funding}

- Ako Aotearoa Regional Hub Project Fund

- North Shore Teachers College Trust

\section{Collaborators}

- Associate Professor Richard Hamilton (co-researcher from the Faculty of

- Sandra Chandler, Jill Murray (collaborators from the Faculty of Education and Social Work, University of Auckland)

\section{ROCK!}

$\left.\sum_{0}, s^{2}\right) \pi$
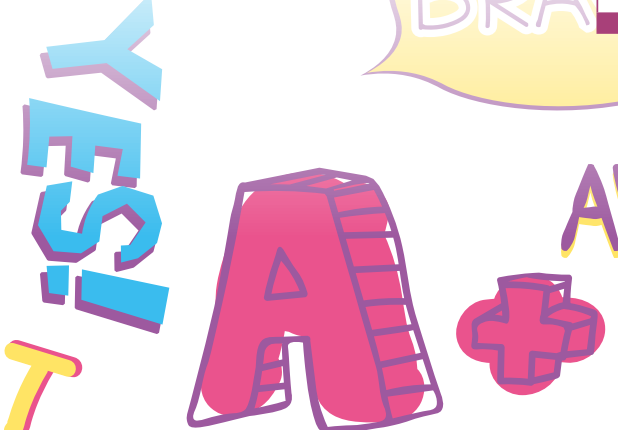

AWESOME

\section{References}

Hawe, E et al (2018). Why lecturers use exemplars and how they use them. Available at: https://ako.ac.nz/assets/ Knowledge-centre/AHF-N68-Why-lecturers-use-exemplars/ Hawe, Eet al (2019). Fis exemplars: promoting self-efficacy, self-monitoring and selfregulation. Journal of Further and Higher Education, 43(1). pp 30-44. https://doi.org/10.1080/0309877X.2017.1349894 Hawe, E et al (2020). Using rubrics and exemplars to develop students' evaluative and productive knowledge and skill. Journal of Further and Higher Education. pp 1-15. https://doi. org/10.1080/0309877X.2020.1851358

Hawe, E et al (2021). Why and how educators use exemplars. Journal of University Teaching and Learning Practice, 18(3). pp 1-13. Available at: https://ro.uow.edu.au/juttp/vol18/iss3/010

\section{Personal Response}

How can students retain originality and creativity while

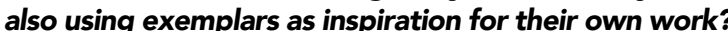

II Firstly, educators should explain why they are using quality work looks like: motivate students) indicating they are not to be copied. Students should be exposed to a range of exemplars (across the spectrum of achievement) so they can see the different ways in which previous cohorts have addressed requirements, solved problems, also talk about how to improve specific exemplars - this encourages students to think creatively and try different ways of addressing requirements. Including originality and/or creativity as criteria in the rubric also signals that there are different ways in which task requirements and
achievement levels can be met. 